\title{
TRADE BETWEEN CREATIVE REGIONS WHEN THE INPUT ELASTICITY OF SUBSTITUTION IS LESS THAN UNITY ${ }^{1}$
}

\author{
Amitrajeet A. BATABYAL \\ Department of Economics, Rochester Institute of Technology, 92 Lomb Memorial Drive, Rochester, \\ NY 14623-5604, USA. \\ aabgsh@rit.edu \\ Hamid BELADI \\ Department of Economics, University of Texas at San Antonio, One UTSA Circle, San Antonio, TX \\ 78249-0631, USA. \\ Hamid.Beladi@utsa.edu
}

\begin{abstract}
$\underline{\text { Abstract }}$
We analyze a model of trade between $J$ heterogeneous regions that are creative in the sense of Richard Florida. There are two non-traded final goods that are used for consumption and investment. There is a continuum of inputs that are freely traded between the creative regions. There is no borrowing or lending between the creative regions. Specifically, we study the impacts of free trade in inputs when the elasticity of substitution between the traded inputs that are used to produce the final consumption and investment goods is less than unity. We first show that creative regions that have lower discount rates will be relatively poor and hence worse off with trade when the above elasticity of substitution is less than one. Next, we explain in detail why this negative result obtains.
\end{abstract}

Keywords: Creative Capital, Creative Region, Elasticity of Substitution, Input, Trade

JEL classification: R11, F12

\section{Introduction}

\subsection{Overview of the issues and the literature}

The publication of two books by the noted urbanist Richard Florida has given rise to great interest among economists and regional scientists in studying the twin notions of the creative class and creative capital. The first book, The Rise of the Creative Class, was released in 2002 and the second book, The Flight of the Creative Class, appeared in 2005. Florida (2002, p. 68) helpfully explains that the creative class "consists of people who add economic value through their creativity." This class consists of professionals such as doctors, lawyers, scientists, engineers, university professors, and, notably, bohemians such as artists, musicians, and sculptors. What differentiates these individuals is that they possess creative capital which is defined to be the "intrinsically human ability to create new ideas, new technologies, new business models, new cultural forms, and whole new industries that really [matter]" (Florida, 2005, p. 32). The creative class is salient, says Florida, because this group generates ideas, information, and technology, outputs that are increasingly significant for the growth of cities and regions. Therefore, cities and regions that want to succeed on the global stage must attempt to attract and retain members of this creative class who are the primary drivers of economic growth.

Researchers have now analyzed various aspects of creative capital and the creative class. Focusing on the Canadian periphery, Petrov (2007) points out that the geographic distribution of creative capital is very uneven and heavily concentrated in major urban centers. McGranahan and Wojan (2007) concentrate on rural counties in the United States and find support for Florida's creative class thesis. Donegan and Lowe (2008) contend that cities with a large creative talent pool are also more likely to have substantial income inequality. Florida et al. (2008) show that the creative class idea outperforms conventional educational attainment measures in accounting for regional labor productivity measured with wages. In contrast, conventional educational attainment measures are a better predictor of regional 
income than the creative class idea. Westlund and Calidoni (2010) concentrate on regional development in Japan and find no significant support for Florida's thesis which they interpret as the idea that a heterogeneous civil society with diverse values including tolerance will have a positive effect on regional development.

Marrocu and Paci (2012) conduct an empirical analysis of Florida's creative class by studying the activities of creative graduates, bohemians, and non-creative graduates. Their analysis shows that if the objective is to explain the economic performance of a region, then the creative graduates have the greatest positive impact, non-creative graduates have a lesser impact, and bohemians have no impact. Gabe et al. (2013) study the employment prospects of three classes of individuals in the United States in the 2006-2011 period. Their analysis shows that relative to members of the service and working classes, members of the creative class had the lowest likelihood of being unemployed during this period. A similar finding about the superior employment prospects of the creative class has been obtained by Currid-Halkett and Stolarick (2013).

The studies discussed in the preceding two paragraphs have advanced our understanding of many aspects of the twin notions of creative capital and the creative class. Even so, these studies have typically analyzed creative regions as closed economies and hence they are silent about the effects of trade between creative regions on the growth and/or the welfare of these same trading regions. Having said this, there is now a growing literature on interregional trade ${ }^{4}$ but, for the most part, this literature has analyzed trade between generic regions and not regions that are creative in the sense of Richard Florida ${ }^{5}$.

Very recently, this unhappy state of affairs has begun to change with the appearance of three papers that have analyzed trade in the context of creative regions. First, Batabyal and Nijkamp (2010) concentrate on a two-sector trading regional economy and provide the first theoretical analysis of the creative capital accumulation decision faced by individuals in this regional economy. Second, Batabyal and Nijkamp (2011) analyze a two-sector model of a trading creative regional economy. Their analysis shows that whether or not faster productivity growth in the tradable sector results in the departure of creative people from this sector to the non-tradable sector is independent of whether this faster productivity growth is neutral or non-neutral. Finally, Batabyal and Beladi (2014) study a model of trade between two creative regions where one region is larger than the other region in terms of its endowment of creative capital and there is sector specific learning by doing. They show that when a specific condition holds, the smaller region specializes completely in the production of what they call input 1 but there is incomplete specialization in the larger region.

\subsection{Relation to previous literature and contributions of our paper}

To the best of our knowledge, the papers discussed in the previous paragraph are the only ones to have theoretically analyzed trade between creative regions. In this paper, we complement the findings in these previous three studies by focusing explicitly on a specific aspect of the functions describing the production of the two final goods in the creative regions under study. This particular aspect is the magnitude of the elasticity of substitution between the various traded inputs that are used to produce the two final goods in the different regions.

The effects of trade when the elasticity of substitution is greater than unity are relatively straightforward to discern from the extant literature on trade between nations ${ }^{6}$. Therefore, in this paper, we focus on the case where the elasticity of substitution is less than unity. Not only has this case not been studied in the literature but, as we show in the remainder of our paper, this "less than unity" case has significant implications for the welfare effects of trade between creative regions.

The remainder of this paper is organized as follows. Section 2 describes the theoretical framework in detail. Section 3 demonstrates that with trade, creative regions that

\footnotetext{
${ }^{4}$ See Horiba (2008), Andresen (2009), Ghemawat et al. (2010), de la Mata and Llano (2013), and de la Mata (2014) for additional details on this literature.

${ }^{5}$ Recall that creative regions are populated by members of the creative class who possess creative capital.

${ }^{6}$ See Acemoglu and Ventura (2002) for additional details on this point.
} 
have lower discount rates will be relatively poor when the above mentioned elasticity of substitution between the various traded inputs is less than one. Section 4 explains in detail why the negative result in section 3 obtains. Finally, section 5 concludes and then suggests two ways in which the research delineated in this paper might be extended.

\section{The Theoretical Framework}

\subsection{Preliminaries}

Our model is adapted from the prior work of Acemoglu and Ventura (2002) and Acemoglu (2009, pp. 663-674). Consider an infinite horizon aggregate economy made up of J creative regions that are indexed with the subscript $j$ where $j=1,2, \ldots, J$. There is a continuum of inputs that we index by $v \in[0, N]$. There are two final goods that are used for consumption and investment. The trade that we study is in inputs ${ }^{7}$ between the different creative regions and there is no trade in the two final goods. There is also no borrowing or lending between the different creative regions.

The creative regions being studied differ in their technology, savings, and economic policies. For the $j$ th creative region, we describe how advanced this region's technology is with $\mu j$, its time preference with $\rho j$, and the effect of its economic policies on the incentive to invest with $\delta j$. The triple $(\mu j, \rho j, \delta j)$ varies across space, i.e., across the different creative regions under study, but it is constant over time.

The representative creative class household in the $j$ th region has a logarithmic utility function described by

$$
\int_{0}^{\infty} e^{-\rho_{j} t} \log \left\{C_{j}(t)\right\} d t
$$

where $C_{j}(t)$ is consumption at time $t$. The representative creative class household in region $\mathrm{j}$ possesses creative capital and the stock of this creative capital at time $\mathrm{t}=0$ is $\boldsymbol{H}_{j}(\boldsymbol{t})>0$. The budget constraint of the representative creative class household in region $j$ at time $t$ is

$$
p_{j}^{I}(t) \dot{H}_{j}(t)+p_{j}{ }^{C}(t) C_{j}(t)=Q_{j}(t)=w_{j}(t) H_{j}(t),
$$

where $p_{j}^{I}(t)$ and $p_{j}^{C}(t)$ are the time $t$ prices of the investment and consumption final goods, $Q_{j}(t)$ is total income, $H_{j}(t)$ is creative capital, and $w_{j}(t)$ is the return to creative capital. ${ }^{8}$ Equation (2) says that expenditures on investment plus consumption (the LHS) equals total income which, in turn, equals the income of creative capital (the RHS). Note that the two prices $p_{j}^{I}(t)$ and $p_{j}^{C}(t)$ will generally differ across the various creative regions because the production functions - on which more below - for the investment and the consumption goods are dissimilar.

The production of the $\mathrm{N}$ inputs in our aggregate economy is split up across the $J$ creative regions. In effect, this means that each input can only be produced in a single creative region. This assumption also has the implication that while each creative region might be small from the standpoint of its import markets, each such region influences its terms of trade by the amount of the inputs it exports. Here, the expression "terms of trade" refers to the price of the exports of a region divided by the price of its imports. Now using the technology proxy $\mu_{j}$ for creative region $j$ described earlier, the above "splitting up" assumption tells us that we can sum over all the creative regions under study and write

$$
\sum_{j=1}^{N} \mu_{j}=N \text {. }
$$

Equation (3) tells us that if the $j$ th creative region has a relatively high $\mu_{j}$ then this means that this $j$ th region has the technology to produce a larger variety of inputs. The various inputs are produced competitively in the different creative regions under study. In addition, we suppose that in each creative region, the production technology of the inputs is such that one

\footnotetext{
7 Jones et al. (2005) have pointed to the importance of trade in inputs in the case where the regions under study are actually nations.

${ }^{8} \mathrm{~A}$ dot above a variable indicates a derivative with respect to time.
} 
unit of creative capital produces one unit of any input that this region is capable of producing. Finally, there is free entry in the production of inputs. Hence all input production in the $J$ creative regions under study is competitive and the prices of the inputs produced in creative region $\mathrm{j}$ are given by

$$
p_{j}(t)=w_{j}(t)
$$

\subsection{The dynamic model}

In any creative region $j$, the consumption and investment final goods are produced using this region's creative capital and a collection of the freely traded inputs available in our aggregate economy. Specifically, the production function for the consumption good is given by

$$
C_{j}(t)=\alpha H_{j}{ }^{C}(t)^{1-\beta}\left\{\int_{0}^{N} x_{j}^{C}(v, t)^{(\gamma-1) / \gamma} d v\right\}^{\beta \gamma(\gamma-1)},
$$

where $\alpha>0$ is a parameter, $H_{j}^{C}(t)$ is the portion of the $j$ th region's creative capital that is used to produce the consumption good, and $\beta \in(0,1)$ is a scale parameter. The expression inside the curly brackets in equation (5) denotes the collection of inputs that are bought from the other creative regions in our aggregate economy and then used to produce the consumption good in region $j$. In this regard, $x_{j}^{C}(v, t)$ is the amount of input $v$ that is used to produce the consumption good $C$ at time $t$. Note that the expression inside the curly brackets in equation (5) involves integrating over all possible inputs in our aggregate economy. The key parameter in equation (5) is $\gamma$ or the elasticity of substitution between the different traded inputs. As noted in section 1, in this paper we shall be concerned with the case in which $\gamma<1$. This is the case in which there is a limited amount of substitutability between the different inputs that are used to produce the final consumption good. Finally, the parameter $\beta$ is in the exponent on the expression inside the curly brackets. Two features of this parameter are worth emphasizing. First, this parameter ensures that the production function in equation (5) exhibits constant returns to scale in creative capital and in the various traded inputs given in the expression inside the curly brackets. Second, we can also interpret $\beta$ as the share of trade in the $j$ th creative region's gross domestic product.

The production function for the investment final good $I_{j}$ is given by

$$
I_{j}(t)=\left(\frac{1}{\delta_{j}}\right) \alpha H_{j}^{I}(t)^{1-\beta}\left\{\int_{0}^{N} x_{j}^{I}(\nu, t)^{\frac{\gamma-1}{\gamma}} d \nu\right\}^{\frac{\beta \gamma}{\gamma-1}},
$$

where the parameter $\delta_{j}>0$ can be thought of as a productivity parameter. In this regard, note that ceteris paribus, a high (low) value of $\delta_{j}$ decreases (increases) the output of the investment good. Inspecting equation (6), we see that except for the $\delta_{j}$ parameter, the production functions for the consumption and investment final goods are identical. Now, for the creative capital market in the $j t h$ region to clear, we must have

$$
H_{j}^{C}(t)+H_{j}^{I}(t)+H_{j}^{\mu}(t) \leq H_{j}(t),
$$

where $H_{j}^{\mu}(\mathrm{t})$ is the portion of creative capital in region $j$ that is used to produce the traded inputs and $H_{j}(t)$ is the total available creative capital in region $j$ at time $t$.

To proceed further, we work with the so called unit cost functions. These functions give us the cost of producing one unit of the consumption and investment final goods in terms of an ideal price index for the traded inputs. Adapting equations 19.27 and 19.28 in Acemoglu $(2009$, p. 667) to our problem, the two unit cost functions we seek are given by

$$
F_{j}^{C}\left[w_{j}(t),\{p(v, t)\}_{v \in[0, N]}\right]=w_{j}(t)^{I-\beta}\left\{\int_{0}^{N} p(v, t)^{I-\gamma} d v\right\}^{\beta /(1-\gamma)}
$$

and

$$
F_{j}^{I}\left[w_{j}(t),\{p(v, t)\}_{v \in[0, N]}\right]=\delta_{j} w_{j}(t)^{1-\beta}\left\{\int_{0}^{N} p(v, t)^{l-\gamma} d v\right\}^{\beta /(1-\gamma)},
$$

where $p(v, t)$ is the price of input $v$ at time $t$. Note that these input prices do not have a region specific subscript because they are freely traded and hence all the regions in our aggregate economy face the same input prices. 
An equilibrium in our aggregate economy of $J$ creative regions arises when all markets clear and the representative household in the creative class in each region $j$ maximizes its utility given the time path of prices. In this regard, maximizing the utilityequation (1) - of the representative creative class household in region $j$, we get the two first order necessary conditions for an optimum in each region $j$ and for all time $t$. These two conditions are

and

$$
\begin{gathered}
\frac{w_{j}(t)+\dot{\mathrm{p}}_{j}^{I}(t)}{p_{j}^{I}(t)}-\frac{\dot{\mathrm{p}}_{j}^{C}(t)}{p_{j}^{C}(t)}=\rho_{j}+\frac{\dot{\mathrm{C}}_{j}(t)}{C_{j}(t)} \\
\lim _{t \rightarrow \infty}\left[e^{-\rho_{j}^{t}}\left\{\frac{p_{j}^{I}(t) H_{j}(t)}{p_{j}^{C}(t) C_{j}(t)}\right\}\right]=0 .
\end{gathered}
$$

Equation (10) is the so called consumption Euler equation ${ }^{9}$. In words, this equation tells us that the net rate of return to creative capital (the LHS) must be equal to the rate of time preference plus the slope of the time path of consumption (the RHS). Equation (11) is the transversality condition that must hold at the end of the maximizing horizon.

Let us integrate the budget constraint in equation (2) and then simplify the result by using the first order necessary conditions in equations (10) and (11). This gives us an equation for the consumption function in region $\mathrm{j}$ and that equation is

$$
p_{j}^{C}(t) C_{j}(t)=\rho_{j}\left\{p_{j}^{I}(t) H_{j}(t)\right\} \text {. }
$$

In words, equation (12) tells us that at any time t, the representative creative class household in any region $\mathrm{j}$ spends a fraction $\rho j$ of its wealth — given in the curly brackets on the RHS - on consumption (the LHS).

We have now described the prices of the traded inputs and the behavior of consumption and the creative capital stock in each region $j$. We now delineate the prices of the consumption and the investment goods and the relative prices of the traded inputs in the aggregate economy. Let us use the ideal price index for the collection of all the traded inputs as our numeraire for the aggregate economy. Since the traded inputs enter the two production and unit cost functions - see equations (5), (6), (8), and (9) - in constant elasticity of substitution or CES form, we can adapt equation 19.32 in Acemoglu $(2009$, p. 668) to our problem and deduce that the ideal price index we seek is given by

$$
\left\{\int_{0}^{N} p(v, t)^{1-\gamma} \mathrm{d} v\right\}^{\frac{1}{1-\gamma}}=1=\sum_{j=1}^{J} \mu_{j} p_{j}(t)^{1-\gamma}
$$

The first equality in (13) defines the ideal price index. The second equality arises from the fact that creative region $j$ produces $\mu_{j}$ inputs and each of these inputs has the same price $p_{j}(t)=w_{j}(t)$ specified in equation (4). In the model that we are studying, each region exports almost all of its production of inputs and it imports the so called "ideal basket" of inputs produced in the aggregate economy. Therefore, the relationship that equation (4) specifies denotes not only the price of the inputs produced by creative region $\mathrm{j}$ but also this region's terms of trade.

Using equation (13), the two unit cost functions in equations (8) and (9) together provide us with expressions for the equilibrium prices of the consumption and investment final goods at any time $t$ in region $j$. These two expressions are

$$
p_{j}^{C}(t)=w_{j}(t)^{I-\beta} \text { and } p_{j}^{I}(t)=\delta_{j} w_{j}(t)^{I-\beta} .
$$

Inspecting equation (14), we see that the prices of the final consumption and investment goods are given in terms of the rate of return to creative capital $w_{j}(t)$.

Next, we discuss the condition that must hold for trade in inputs between the $J$ creative regions in our aggregate economy to be balanced. To derive this condition, note the following four points. First, since each creative region $j$ is assumed to be small, this region spends a fraction $\beta$ of its income $Q_{j}(t)$ on imports. Second, the remaining $J-1$ regions in our aggregate economy together spend the fraction $\beta \mu_{j} p_{j}(t)^{l-\gamma}$ of their income on the inputs produced by

\footnotetext{
${ }^{9}$ See Acemoglu (2009, pp. 209-210) or Aghion and Howitt (2009, pp. 34-37) for textbook expositions of the consumption Euler equation.
} 
region $j$. Third, the income of our aggregate economy is simply $Q(t)=\sum_{j=1}^{J} Q_{j}(t)$. Fourth, the terms of trade for creative region $j$ are given by equation (4). Putting these four pieces of information together, we deduce that the trade balance equation we seek is given by

$$
Q_{j}(t)=\mu_{j} w_{j}(t)^{1-\gamma} Q(t)
$$

The equations (2), (4), (12), (14), and (15) together fully describe the equilibrium in the aggregate economy we have been studying thus far.

Our final task in this section consists of two steps. In the first step, we delineate the state of our aggregate economy by describing the temporal evolution of the stock of creative capital for any creative region $j=1, \ldots, J$. To do this, we first combine equations (2), (12), and (14) and then combine equations (2) and (15). After some algebra, we see that the evolution of the creative capital stock is given by

and

$$
\begin{gathered}
\frac{\dot{H}_{j}(t)}{H_{j}(t)}=\frac{w_{j}(t)^{\beta}}{\delta_{j}}-\rho_{j}, \\
w_{j} H_{j}(t)=\mu_{j} w_{j}(t)^{l-\gamma} \sum_{i=1}^{J} w_{i}(t) H_{i}(t) .
\end{gathered}
$$

In the second step, we adapt proposition 19.10 in Acemoglu (2009, p. 669) to our problem and deduce that there exists a unique and (saddle-path) stable steady state aggregate economy equilibrium in which the steady state return to creative capital and the terms of trade in region $j$ are given by

$$
w_{j}^{S S}=p_{j}^{S S}=\left\{\delta_{j}\left(p_{j}+g^{S S}\right)\right\}^{\frac{1}{\beta}},
$$

where the superscript SS denotes the steady state and $g^{s S}=H_{j}^{\prime}(t) / H_{j}(t)=\phi_{j}(t) / Q_{j}(t)$ refers to the steady state growth rate of our aggregate economy. We are now in a position to shed light on the effects of trade in inputs on creative regions that have relatively low discount rates, given that the elasticity of substitution between the traded inputs or $\gamma<1$. $^{10}$

\section{Low Discount Rates and the Effects of Trade}

Note that even when the elasticity of substitution between the traded inputs or $\gamma<1$, the resulting equilibrium is still given by the various equations described in section 2.2 above. However, to see what happens to a creative region with a relatively low discount rate $\rho_{j}$, let us substitute equation (18) into equation (15). This gives us an expression for the steady state output of creative region $j$ relative to the steady state output of the aggregate economy. Specifically, we get

$$
\left\{\frac{Q_{j}(t)}{Q(t)}\right\}^{S S}=\mu_{j}\left\{\delta_{j}\left(\rho_{j}+g^{S S}\right)\right\}^{(1-\gamma) / \beta} .
$$

Inspecting equation (19), it is clear that because $\beta \in(0,1)$ and $1-\gamma>0$, ceteris paribus, trading creative regions with lower discount rates will be relatively poor and hence worse off. We now explain in detail why this negative result holds.

\section{Why Some Creative Regions are Relatively Poor}

To comprehend the negative result in section 3, note first that regions with relatively low discount rates have higher levels of creative capital, a lower return to creative capital, and relatively cheaper export goods. In the case where the elasticity of substitution $\gamma<1$, creative regions with relatively cheaper export goods receive a smaller share of the aggregate economy expenditure on exports and, controlling for the technology parameter $\mu_{j}$, earn lower export revenues.

The effects described in the preceding paragraph can be seen clearly by inspecting equation (17). We see that when $p_{j}(t)$ and hence-from equation (4) - $w_{j}(t)$ is low, $w_{j}(t)^{1-\gamma}$ is also low and this decreases the $j$ th region's share of the income of the aggregate economy. Put differently, when the elasticity of substitution $\gamma<1$, the demand for each traded input is

${ }^{10}$ In what follows, we adapt some of the discussion in Peters and Simsek (2009, pp. 416-417). 
inelastic enough so that increasing the price does not decrease the demand much and lead to higher profits. In other words, creative regions with low discount rates and low export prices receive lower export revenues and hence lower income. These findings tell us that creative regions with low discount rates grow faster and as a result of this faster growth, the price of their goods decreases so much that the fast growth ends up making them relatively poorer and hence worse off. In this sense, this result is similar to the prominent "immiserizing growth" result obtained by Bhagwati (1958).

To comprehend this "immiserizing growth" result in a different way, let us focus on two of our assumptions in the model that we have been studying thus far. First, we assumed that the production of all the consumption and investment goods required the use of inputs which had to be imported from other regions. As a result, accumulating creative capital in any region $j$ did not lead to output growth in this same region because the region's production technology depended on imports which the region had to finance through its own exports. Second, with the elasticity of substitution $\gamma<1$, the demand for a creative region's inputs is inelastic enough so that too much production results in potent price effects which, in turn, reduce export revenues. With lower export revenues, the $j$ th region can import less and hence produce less. Therefore, these two assumptions together lead to the above mentioned "immiserizing growth" result. This concludes our discussion of trade between creative regions when the elasticity of substitution between the various traded inputs $\gamma$ is less than unity.

\section{Conclusions}

In this paper, we analyzed a model of trade between $J$ heterogeneous regions that were creative in the sense of Richard Florida. There were two final goods that were not traded but were used for consumption and investment. There was a continuum of inputs that were freely traded between the creative regions. There was no borrowing or lending between the creative regions. Specifically, we studied the impacts of free trade in inputs when the elasticity of substitution between the various traded inputs $\gamma$ that were used to produce the final consumption and investment goods was less than unity. We first showed that in the presence of trade, creative regions that had lower discount rates would be relatively poor when $\gamma$ was less than one. Next, we provided a detailed explanation of the rationale for this negative result.

The analysis in this paper can be extended in a number of different directions. In what follows, we suggest two possible extensions. First, it would be useful to compare the results of this paper with those obtained in a setting in which each creative region operates as a closed economy. In this closed economy scenario, each creative region would only use the inputs it produced in the region, to produce consumption and investment goods. Second, it would also be instructive to compare and contrast the findings of this paper with a scenario in which a region specific social planner makes consumption and production decisions in each of the $J$ creative regions. Studies that analyze these aspects of the underlying problem will provide additional insights into the nexuses between alternate consumption and production structures and the functioning of creative regions that are also open economies.

\section{$\underline{\text { References }}$}

Acemoglu, D. 2009. Introduction to Modern Economic Growth. Princeton University Press, Princeton, NJ.

Acemoglu, D., and Ventura, J. 2002. The world income distribution, Quarterly Journal of Economics, 117, 659-694.

Aghion, P., and Howitt, P. 2009. The Economics of Growth. MIT Press, Cambridge, MA.

Andresen, M.A. 2009. Canada-U.S. interregional trade, 1989-2001, Canadian Journal of Regional Science, 32, 187-202.

Batabyal, A.A., and Beladi, H. 2014. A model of trade between creative regions in the presence of sector specific learning by doing, Journal of Evolutionary Economics, 24, 573585. 
Batabyal, A.A., and Nijkamp, P. 2010. Richard Florida's creative capital in a trading regional economy: A theoretical investigation, Annals of Regional Science, 44, 241-250.

Batabyal, A.A., and Nijkamp, P. 2011. The impact of neutral and non-neutral productivity growth on creative capital in a trading regional economy, Geographical Analysis, 43, 6177.

Bhagwati, J.N. 1958. Immiserizing growth: A geometrical note, Review of Economic Studies, 25, 201-205.

Currid-Halkett, E., and Stolarick, K. 2013. Baptism by fire: Did the creative class generate economic growth during the crisis? Cambridge Journal of Regions, Economy, and Society, $8,55-69$.

de la Mata, T. 2014. Does trade creation by social and business networks hold in services? Applied Economics, 46, 1509-1525.

de la mata, T., and Llano, C. 2013. Social networks and trade of services: Modelling interregional flows with spatial and network autocorrelation effects, Journal of Geographical Systems, 15, 319-367.

Donegan, M., and Lowe, N. 2008. Inequality in the creative city: Is there still a place for 'oldfashioned' institutions? Economic Development Quarterly, 22, 46-62.

Florida, R. 2002. The Rise of the Creative Class. Basic Books, New York, NY.

Florida, R. 2005. The Flight of the Creative Class. Harper Business, New York, NY.

Florida, R., Mellander, C., and Stolarick, K. 2008. Inside the black box of regional development - human capital, the creative class, and tolerance, Journal of Economic Geography, 8, 615-649.

Gabe, T., Florida, R., and Mellander, C. 2013. The creative class and the crisis, Cambridge Journal of Regions, Economy, and Society, 6, 37-53.

Ghemawat, P., Llano, C., and Requena, F. 2010. Competitiveness and interregional as well as international trade: The case of Catalonia, International Journal of Industrial Organization, $28,415-422$.

Horiba, Y. 2008. U.S. interregional trade and migration, Osaka Economic Papers, 58, 159171.

Jones, R., Kierzkowski, H., and Lurong, C. 2005. What does evidence tell us about fragmentation and outsourcing? International Review of Economics and Finance, 14, 305316.

Marrocu, E., and Paci, R. 2012. Education or creativity: What matters most for economic performance? Economic Geography, 88, 369-401.

McGranahan, D., and Wojan, T. 2007. Recasting the creative class to examine growth processes in rural and urban counties, Regional Studies, 41, 197-216.

Peters, M., and Simsek, A. 2009. Solutions Manual for Introduction to Modern Economic Growth. Princeton University Press, Princeton, NJ.

Petrov, A.N. 2007. A look beyond metropolis: Exploring creative class in the Canadian periphery, Canadian Journal of Regional Science, 30, 451-474.

Westlund, H., and Calidoni, F. 2010. The creative class, social capital, and regional development in Japan, Review of Urban and Regional Development Studies, 22, 89-108. 